\title{
Reliability and Validity of a French Version of the Posttraumatic Growth Inventory
}

\author{
Susan Cadell ${ }^{*}$, Eliana Suarez ${ }^{2}$, David Hemsworth ${ }^{3}$ \\ ${ }^{1}$ School of Social Work, Renison University College, University of Waterloo, Waterloo, Canada \\ ${ }^{2}$ Faculty of Social Work, Wilfrid Laurier University, Waterloo, Canada \\ ${ }^{3}$ Faculty of Applied \& Professional Studies, School of Business \& Economics, Nipissing University, North Bay, \\ Canada \\ Email: scadell@uwaterloo.ca, esuarez@wlu.ca, davidhe@nipissingu.ca
}

Received 2 March 2015; accepted 15 April 2015; published 16 April 2015

Copyright (C) 2015 by authors and Scientific Research Publishing Inc.

This work is licensed under the Creative Commons Attribution International License (CC BY). http://creativecommons.org/licenses/by/4.0/ c) (i) Open Access

\begin{abstract}
In the context of traumatic stress, the dominant discourse has mainly focused on distress, thus undermining the role that eustress has in traumatic experiences. One of the few exceptions to this has been the research on posttraumatic growth, which has generated much interest since its beginning. There is an increasing interest in posttraumatic growth in various cultures and hence an expansion of the measure, the Post Traumatic Growth Inventory (PTGI), into various languages. This article is the first to perform a rigorous investigation of the psychometric properties of the PTGI, including the scale and subscale reliability, inter-item and subscale correlations, and using a CFA approach. The properties are established with a French translation using two populations of caregivers: those bereaved by HIV/AIDS and parents who are caring for a child with a life-limiting illness. These properties were determined for both the original 21 item scale as well as the shortened version.
\end{abstract}

\section{Keyword}

Posttraumatic Growth Inventory

\section{Introduction}

The field of traumatic stress is intimately connected with both trauma and stress theories. The original conceptualization of stress by Selye [1] considered stress to be an adaptive response in that small dosages of stress could be positive because it produced better coping and/or functioning of the individual. Indeed, positive stress is referred to as eustress, whereas the negative side is distress, which can impair functioning and well-being. In the context of traumatic stress, the dominant discourse has mainly focused on distress, thus undermining the role that

${ }^{*}$ Corresponding author.

How to cite this paper: Cadell, S., Suarez, E. and Hemsworth, D. (2015) Reliability and Validity of a French Version of the Posttraumatic Growth Inventory. Open Journal of Medical Psychology, 4, 53-65.

http://dx.doi.org/10.4236/ojmp.2015.42006 
eustress has in traumatic experiences [2]. One of the few exceptions to this has been the research on posttraumatic growth (PTG), which is defined as the positive consequences of struggling to understand traumatic stress [3].

The last decade has seen much interest in the study of posttraumatic growth. Numerous reviews have been published [4]-[9]. Meta-analyses have appeared concerning factors relating to posttraumatic growth [10] and health and other outcomes [11]. The field of traumatic stress is evolving to encompass psychological thriving, not just surviving trauma.

It is now widely acknowledged that there can be positive aspects of stressful experiences. After studying only the pathology of stress and trauma for years, researchers are now incorporating strengths, hence examining the whole experience [12] [13]. Several studies (e.g. [14]-[16]) suggest a reciprocal and complex relationship between PTG and markers of psychological distress, including Posttraumatic Stress Disorder (PTSD); this emerging understanding points to the importance of further research on PTG. Our research on caregivers has recently pointed to the central importance of meaning-making in growth [17] [18].

In particular, there is an increasing interest in posttraumatic growth in various cultures and hence an expansion of the most commonly used measure, the Post Traumatic Growth Inventory (PTGI) [3], into various languages. For instance, Weiss and Berger [19] contributed the Spanish translation of the PTGI. Careful assessment of translated measures is crucial because invalid mental health measures can lead to misguided interventions, which may exacerbate existing health and mental health care disparities.

With such focus, this paper establishes the psychometric properties of a French translation of the PTGI with two populations of caregivers: those bereaved by HIV/AIDS and parents who are caring for a child with a lifelimiting illness. Despite seemingly disparate populations, they share the stresses of caring for someone ill. Caregiving is not often construed to be traumatizing, but is known to be stressful; indeed, the stresses are cumulative. There is evidence of PTG in these populations [12] [14], which may further broaden the discussion of stressful events and their relationship with traumatic stress [20] [21]. For these two populations, the properties of the French translation were determined for both the original PTGI scale and the shortened version, the PTGI-SF.

\section{Literature Overview}

The Post Traumatic Growth Inventory (PTGI) [3] was developed after the realization that the positive changes experienced in the aftermath of stressful events were under-recognized. The PTGI consists of 21 items, and the response scale is a 6-point Likert scale asking respondents the degree to which changes occurred in their lives as a result of the crisis, where 0 represented "I did not experience this change" and 5 represented "I experienced this change to a very great degree". The PTGI is composed of 5 subscales, with 5 items measuring the construct New Possibilities, 7 items measuring the construct Relating to Others, 4 items measuring the construct Personal Strength, 3 items measuring the construct Appreciation of Life and 2 items measuring the construct Spiritual Change. A similar factor structure was confirmed in the shortened ten item version (PTGI-SF) [22].

The PTGI has been validated in numerous languages and populations. For instance, the Portuguese translation was used with adult children of parents with cancer and a control group [23]. The Japanese version was used to examine posttraumatic growth in university students [24]. The Dutch [25] and the Chinese [26] translations have been validated with cancer survivors. The Spanish version [19] was confirmed with Latina immigrants in the United States, while the Bosnian one was used with former refugees and displaced people in Sarajevo [27]. German [28] and Hebrew [29] versions also exist. Lelorain, Bonnaud-Antignac, and Florin [30] describe a form of the PTGI; however, no published version of the PTGI in French has been found.

One thing that is clearly missing in the PTG literature surrounding this scale is a rigorous and systematic analysis of the psychometric properties of the PTGI with respect to these translation articles. All of the papers reported the reliability (in the form of Cronbach's Alpha); however, only two reported the reliability of its five subscales. Similarly, only three (the Dutch [25], Portuguese [23] and Japanese [24] translations) attempted inter-item correlations which were used to aid in establishing the viability of a scale. Moreover, five of the papers used exploratory factor analyses (EFA), although this was not the recommended technique to confirm a hypothesized factor structure [31]-[33]. Since this technique is data-driven and is not constrained to a specific factor structure and item loading, it is impossible to compare the appropriateness of the five-factor and item structure proposed for the scale by Tedeschi and Calhoun [3] in different translations.

\section{Method}

The data were derived from two separate studies investigating posttraumatic growth in caregivers. The same 
French language version was used for both groups. Ethical approval was obtained for both studies from all relevant institutions.

\subsection{Translation Procedures}

The original PTGI was translated from English to French by a professional translator. The French version was then independently back-translated into English by a different certified translator. The two versions were checked for accuracy and no differences were found. The content was validated independently by a native French speaker. This method of scale translation was similar to that used by Lucas-Carrasco, Gomez-Benito, Rejas, and Brod [34].

\subsection{Sample One: Bereaved HIV/AIDS Caregivers}

The study was performed with individuals who had cared for or about someone who had died with HIV-related illness. Full details of the method and demographics of the sample are reported elsewhere [14] [35]-[38]. The overall sample of 176 participants was recruited through posters at HIV/AIDS conferences and service organisations; a toll-free number allowed people to volunteer through no cost to themselves. The full questionnaire package was mailed out with an addressed return envelope and \$20 to thank them for their participation. The questionnaire included a demographics form, the PTGI and various other measures for a total of 15 pages. The total number of questionnaires mailed out was 202. One hundred and seventy-six (86.7\%) were returned. Of these, 10 of the questionnaires were completed in French.

\subsection{Sample Two: Parents Caring for a Child with a Life-Limiting Illness}

The second study sought to understand the factors in the posttraumatic growth of parents who are caring for a child with a life-limiting illness. Parents were recruited through participating hospitals, hospices and organizations in both the USA and Canada through letters, posters or website postings. The parents volunteered by leaving a message at a toll free number. Their calls were returned, the study explained and if they accepted to participate, a questionnaire, along with $\$ 20$ to thank them, was mailed out. The questionnaire of 15 pages comprised demographics, the PTGI and numerous other measures. In total, 339 parents were recruited. The return rate was $82.6 \%(n=280$ packages $)$, but 7 packages were unusable, so the final sample size was 273 . Of these, 37 of the questionnaires were completed in French; all were from Canadian households. Overall demographic information and results have been reported elsewhere [14] [18] [39].

\subsection{Data Analysis}

The overall French sample was 47 with 10 bereaved HIV caregivers and 37 parents caring for a child with a life-limiting illness and was used to determine the psychometric properties of the PTGI and the PTGI-SF. The English sample was composed of 257 parents caring for a child with a life-limiting illness and was used for comparison to the French sample.

Before combining the data from the two study groups a MANOVA was conducted using the 21 items to determine if there was any significant difference between the groups. This analysis found that there were no significant differences $F(21,25)=1.39, p=0.22$, and thus it is reasonable to combine the two caregiver samples and consider them homogenous.

A post-hoc power analysis was computed using the average number of indicators, average $\mathrm{R}^{2}$, as well as the minimum $R^{2}$ value for each of the 5 subscale CFA factor analyses. The power scores for the average and minimum $\mathrm{R}^{2}$ for each of the scales were: Personal strength avg. $=1.0$, Min. $=0.95$; ReLoth avg. $=1$, min. $=0.82$; New possibilities avg. $=1.0, \mathrm{~min} .=0.99 ;$ Appreciation of life and Spirituality avg. $=1.0, \mathrm{~min} .=0.91$. All power values were over the recommended threshold of 0.80 and thus the sample size was sufficient for determining the effects for the CFA analysis.

Comparisons between the French sample $(n=47)$ and the English sample $(n=257)$ were conducted on the composite scores of each of the 5 PTGI subscales and it was found that there were no significant differences between the mean scores on any of the 5 subscales (the personal strength subscale did show a trend). See Table 1 for results. Differences between the levels of the French and English subscales are not necessary to establish the psychometric integrity of the French scale, but do however give an indication of the similarity between the two populations. 
Table 1. T-test comparison of French and English composite PTGI scores.

\begin{tabular}{|c|c|c|c|c|c|c|c|c|}
\hline \multicolumn{4}{|c|}{ English } & \multicolumn{3}{|c|}{ French } & \multirow[b]{2}{*}{$t$-value } & \multirow[b]{2}{*}{$p$-value } \\
\hline PTGI subscale & M & $S D$ & $\mathrm{n}$ & M & $S D$ & $\mathrm{n}$ & & \\
\hline Relating to others & 2.93 & 1.04 & 259 & 2.72 & 1.13 & 47 & 1.15 & 0.253 \\
\hline New possibilities & 2.76 & 1.26 & 259 & 2.63 & 1.35 & 47 & 0.59 & 0.555 \\
\hline Personal strength & 3.30 & 1.20 & 259 & 2.91 & 1.26 & 47 & 1.98 & 0.052 \\
\hline Spirituality & 2.33 & 1.76 & 259 & 2.53 & 1.63 & 47 & -0.77 & 0.444 \\
\hline Appreciation of life & 3.59 & 1.15 & 259 & 3.30 & 1.15 & 47 & 1.62 & 0.110 \\
\hline
\end{tabular}

M: mean; $S D$ : Standard Deviation; n: sample size.

We tested to determine the psychometric properties of our translation of the PTGI and if the original theorized five-factor structure fit the data collected from our French-speaking participants. In order to establish this, we performed inter-item correlations, tests of reliability, and both convergent and discriminant validity analyses of the PTGI scale and subscales. Similarly, we also tested the 10-item short form in translation.

\section{Results}

\subsection{Inter-Item Correlations}

The inter-item correlations were calculated for each set of items within each of the 5 subscales. All were significantly inter-correlated within their corresponding subscales $(p<0.05)$ except for item 12 which had no significant correlations with other items in the Personal Strength subscale. The average inter-item correlations for the subscales were: New Possibilities $\mathrm{r}=0.50$, Relating to others $\mathrm{r}=0.45$, Personal Strength $\mathrm{r}=0.33$, Appreciation of Life, $\mathrm{r}=0.36$ Spiritual Change, $\mathrm{r}=0.76$. The average inter-subscale correlation for the 5 subscales was $\mathrm{r}$ $=0.45$. The average inter-item correlation for the 21 items was $r=0.40$. It is of note that the inter-item correlation of the 20 items and item 12 was $r=0.13$ which was substantially lower than the average inter-item correlation for the entire subscale.

\subsection{Reliability}

Scale reliability provides a measure of the internal consistency and homogeneity of the items comprising a scale [40]; it was calculated using Chronbach's alpha. The first step in establishing the scale reliability of the PTGI was determining the overall reliability of the 21 items. This was calculated at $\alpha=0.87$, indicating a high level of internal consistency. Next, the reliability of all 5 PTGI subscales was calculated. As seen in Table 2, with one exception, each subscale displayed reliability values in excess of 0.70 , and were above the recommended minimum of 0.60 for exploratory studies [40], providing evidence supporting the reliability of the subscales. With respect to the 4 item subscale Personal Strength it had an internal reliability of $\alpha=0.34$. As identified in the inter-item correlation analysis, item 12 had insignificant inter-item correlations with the other items in the Personal Strength subscale. When this item was removed, the subscale had an internal reliability of $\alpha=0.77$.

In some circumstances a composite score of the subscales is desired rather than the individual item scores (e.g., using the PTGI scale in structural equation modeling where it is only one of the measurements scales), so for completeness we analyzed the psychometric properties of composite subscales. This was accomplished by forming average composite values for each of the five subscales from their corresponding items and calculating the PTGI's reliability with respect to its composite subscales values. This produced composite variables (CV1 to CV5, in Table 3) representing the five constructs that compose the PTGI. For example, the mean of the responses from questions $3,7,11,14$, and 17 was computed to determine the composite for New Possibilities. The reliability of the 5 PTGI composites was $\alpha=0.82$, once again demonstrating a high level of internal consistency of the French translation of the PTGI scale.

\subsection{Validity}

Convergent and discriminant validity are both necessary to demonstrate the validity of a scale. Convergent vali- 
Table 2. Convergent validity and reliability for the post traumatic growth inventory. Survey items are grouped according to subscale and in the first column we see the original question number $(\mathrm{Q})$ which corresponds to the order in which the questions are positioned in the PTGI. The French translation is inserted below each original item.

\begin{tabular}{|c|c|c|c|c|c|}
\hline & Construct/item $(\mathrm{n}=47)$ & $\begin{array}{l}\text { Item } \\
\text { mean }\end{array}$ & $\begin{array}{l}\text { Standardized } \\
\text { coefficient }\end{array}$ & $t$-value & $p$-value \\
\hline \multicolumn{6}{|c|}{$\begin{array}{l}\text { New possibilities }(\alpha=0.83) \chi^{2}=5.26, \mathrm{df}=3, p=0.385, \mathrm{RMSEA}=0.3 \\
\mathrm{NFI}=0.95, \mathrm{RMSEA}=0.03, \mathrm{CFI}=0.99, \mathrm{IFI}=0.99, \mathrm{NNFI}=0.98 \text { and } \mathrm{RMR}=0.04\end{array}$} \\
\hline Q3 & $\begin{array}{l}\text { I developed new interests. } \\
\text { J'ai de nouveaux centres d'intérêt. }\end{array}$ & 2.53 & 0.84 & 6.58 & $<0.05$ \\
\hline Q7 & $\begin{array}{l}\text { I established a new path for my life. } \\
\text { J'ai donné une nouvelle orientation à ma vie. }\end{array}$ & 2.83 & 0.69 & 5.01 & $<0.05$ \\
\hline Q11 & $\begin{array}{l}\text { I'm able to do better things with my life. } \\
\text { Je suis capable de faire de meilleures choses dans ma vie. }\end{array}$ & 2.53 & 0.64 & 4.55 & $<0.05$ \\
\hline Q14 & $\begin{array}{l}\text { New opportunities are available which wouldn't have been otherwise. } \\
\text { De nouvelles opportunités sont apparues, ce qui n'aurait pas été le cas auparavant. }\end{array}$ & 2.47 & 0.74 & 5.51 & $<0.05$ \\
\hline Q17 & $\begin{array}{l}\text { I'm more likely to try to change things which need changing. } \\
\text { Je suis plus encliné(e) à changer ce qui doit l'être. }\end{array}$ & 2.79 & 0.67 & 4.83 & $<0.05$ \\
\hline \multicolumn{6}{|c|}{$\begin{array}{r}\text { Relating to others }(\alpha=0.85) \chi^{2}=18.32, \mathrm{df}=12, p=0.10 \\
\mathrm{NFI}=0.93, \mathrm{RMSEA}=0.10, \mathrm{CFI}=0.97, \mathrm{IFI}=0.97, \mathrm{NNFI}=0.95 \text { and } \mathrm{RMR}=0.08\end{array}$} \\
\hline Q6 & $\begin{array}{l}\text { I more clearly see that I can count on people in times of trouble. } \\
\text { Je me rends mieux compte que je peux compter sur les autres en cas de problème. }\end{array}$ & 2.40 & 0.76 & 10.00 & $<0.05$ \\
\hline Q8 & $\begin{array}{l}\text { I have a greater sense of closeness with others. } \\
\text { Je me sens plus proche des autres. }\end{array}$ & 2.51 & 0.88 & 17.85 & $<0.05$ \\
\hline Q9 & $\begin{array}{l}\text { I have a greater willingness to express my emotions. } \\
\text { J'exprime plus volontiers mes émotions. }\end{array}$ & 2.57 & 0.73 & 6.71 & $<0.05$ \\
\hline Q15 & $\begin{array}{l}\text { I have greater compassion for others. } \\
\text { J'ai davantage de compassion pour les autres. }\end{array}$ & 3.23 & 0.51 & 3.54 & $<0.05$ \\
\hline Q16 & $\begin{array}{l}\text { I put more effort into my relationships. } \\
\text { Je fais davantage d'efforts dans mes relations. }\end{array}$ & 2.66 & 0.61 & 3.99 & $<0.05$ \\
\hline Q20 & $\begin{array}{l}\text { I learned a great deal about how wonderful people are. } \\
\text { J'ai appris à quel point les gens peuvent être merveilleux. }\end{array}$ & 2.98 & 0.70 & 6.04 & $<0.05$ \\
\hline Q21 & $\begin{array}{l}\text { I better accept needing others. } \\
\text { J'accepte mieux d'avoir besoin des autres. }\end{array}$ & 2.68 & 0.71 & 6.71 & $<0.05$ \\
\hline \multicolumn{6}{|c|}{$\begin{array}{c}\text { Personal strength }\left(\alpha=0.77^{*}\right) \chi^{2}=0.02, \mathrm{df}=1, p=0.88 \\
\mathrm{NFI}=1.0, \mathrm{RMSEA}=0.000, \mathrm{CFI}=1.0, \mathrm{IFI}=1.0, \mathrm{NNFI}=1.0 \text { and } \mathrm{RMR}=0.00\end{array}$} \\
\hline Q4 & $\begin{array}{l}\text { I have a greater feeling of self-reliance. } \\
\text { Je compte davantage sur moi. }\end{array}$ & 2.62 & 0.79 & 4.74 & $<0.05$ \\
\hline Q10 & $\begin{array}{l}\text { I know better that I can handle difficulties. } \\
\text { Je sais davantage que je peux faire face aux difficultés. }\end{array}$ & 2.87 & 0.56 & 3.40 & $<0.05$ \\
\hline Q12 & $\begin{array}{l}\text { I am better able to accept the way things work out. } \\
\text { J'accepte plus facilement la tournure que prennent les événements. }\end{array}$ & 3.72 & 0.76 & 6.56 & $<0.05$ \\
\hline Q19 & $\begin{array}{l}\text { I discovered that I'm stronger than I thought I was. } \\
\text { J'ai découvert que j'étais plus fort(e) que je ne le pensais. }\end{array}$ & 3.34 & 0.62 & 4.33 & $<0.05$ \\
\hline \multicolumn{6}{|c|}{$\begin{array}{c}\text { Appreciation of life }(\alpha=0.64) \chi^{2}=5.63, \mathrm{df}=4, p=0.228 \\
\mathrm{NFI}=0.94, \mathrm{RMSEA}=0.09, \mathrm{CFI}=0.98, \mathrm{IFI}=0.98, \mathrm{NNFI}=0.95 \text { and } \mathrm{RMR}=0.05\end{array}$} \\
\hline Q1 & $\begin{array}{l}\text { I changed my priorities about what is important in life. } \\
\text { Mes priorités ont changé. }\end{array}$ & 2.94 & 0.54 & 3.21 & $<0.05$ \\
\hline Q2 & $\begin{array}{l}\text { I have a greater appreciation for the value of my own life. } \\
\text { J'apprécie mieux la valeur de ma vie. }\end{array}$ & 3.47 & 0.55 & 3.07 & $<0.05$ \\
\hline Q13 & $\begin{array}{l}\text { I can better appreciate each day. } \\
\text { J'apprécie davantage le présent. }\end{array}$ & 3.49 & 0.82 & 5.81 & $<0.05$ \\
\hline \multicolumn{6}{|c|}{$\begin{array}{l}\text { Spiritual change }(\alpha=0.86) \chi^{2}=5.63, \mathrm{df}=4, p=0.228 \text { (confirmed with above) } \\
\mathrm{NFI}=.94, \mathrm{RMSEA}=0.09, \mathrm{CFI}=0.98, \mathrm{IFI}=0.98, \mathrm{NNFI}=0.95 \text { and } \mathrm{RMR}=0.05\end{array}$} \\
\hline Q5 & $\begin{array}{l}\text { I have a better understanding of spiritual matters. } \\
\text { Je comprends mieux ce qui a trait à la spiritualité. }\end{array}$ & 2.70 & 0.78 & 5.34 & $<0.05$ \\
\hline Q18 & $\begin{array}{l}\text { I have a stronger religious faith. } \\
\text { Ma foi s'est renforcée. }\end{array}$ & 2.36 & 1.00 & 8.22 & $<0.05$ \\
\hline
\end{tabular}

\footnotetext{
${ }^{*}$ Question 12 omitted from calculation, $\alpha=0.34$ when not omitted.
} 
Table 3. Convergent validity and reliability of the composite PTGI subscales (confirmatory factor analysis).

\begin{tabular}{|c|c|c|c|c|c|}
\hline & Construct/item $(n=47)$ & $\begin{array}{c}\text { Subscale } \\
\text { mean }\end{array}$ & $\begin{array}{c}\text { Standardized } \\
\text { coefficient }\end{array}$ & $t$-value & $p$-value \\
\hline \multicolumn{6}{|c|}{$\begin{aligned} \text { PTGI Subscales }(\alpha=0.82) & \chi^{2}=5.63, \mathrm{df}=4, p=0.228 \\
\text { RMSEA }=0.11, \mathrm{CFI} & =0.97, \mathrm{IFI}=0.97, \mathrm{NNFI}=0.99 \text { and } \mathrm{RMR}=0.08\end{aligned}$} \\
\hline CV1 & New possibilities & 2.63 & 0.83 & 3.51 & $<.05$ \\
\hline CV2 & Relating to others & 2.72 & 0.87 & 3.84 & $<.05$ \\
\hline CV3 & Personal strength & 3.14 & 0.57 & 2.19 & $<.05$ \\
\hline CV4 & Appreciation of life & 3.30 & 0.32 & 3.72 & $<.05$ \\
\hline CV5 & Spiritual change & 2.53 & 0.62 & 2.79 & $<.05$ \\
\hline
\end{tabular}

dity is demonstrated when a set of alternative measures accurately represents the construct of interest [40]. For this study, convergent validity was assessed reviewing the level of significance for the factor loadings using a confirmatory factor analysis (CFA) of the items of each of the 5 PTGI subscales. If all the individual item's factor loadings are significant in CFA, then the indicators are effectively measuring the same construct [41] and the construct is unidimensional. For each subscale the chi-square $\left(\chi^{2}\right)$ was calculated to establish that each of the CFA models fit. As can be seen in Table 2, the chi-square values were all non-significant. A non-significant chisquare value $\left(p\left(\chi^{2}\right)>0.05\right)$ indicates that the covariance structure implied by the model does not significantly vary from the covariance structure calculated from our French data set and hence the CFA models fits. Similarly as reported in Table 2, the fit estimates indicated good fit. With respect to the standardized coefficients from the CFA of the 21 items in the 5 subscales were moderately large and significant ( $t$-values $>2.576 ; p<0.05)$. This indicates that all subscale items significantly contribute and converge on a single subscale construct and that construct is unidimensional. The final step in establishing the convergent validity of the PTGI scale was to perform an overall CFA on the 5 subscales. In Table 3, we see that CFA model fit well ( $\chi^{2}=5.63, d f=4, p=0.228$ ) and the standardized coefficients were moderately large $(\lambda=0.32-\lambda=0.87)$ and significant $(p<0.05)$ indicating that 5 subscale converge to measure the PTGI construct. In summary, the results provide satisfactory evidence of convergent validity for the indicators used to measure the PTGI and its subscales.

To establish that each of the five PTGI subscales is a distinct construct, we conducted a discriminant analysis using a CFA. Discriminant validity among the latent variables and their associated measurement variables can be assessed by fixing the correlation between pairs of constructs to 1.0, then re-estimating the modified model [42]. By constraining the correlation between the two constructs to 1.0 we are essentially converting a two-construct model into a single-construct model. The condition of discriminant validity is met if the difference of the chi-square statistics between the constrained and standard models is significant (1 df). As seen in Table 4, the inter-subscale correlations calculated in the CFA are significant $(p<0.05)$ but moderate, ranging between $r=$ 0.17 and $r=0.41$. Very large inter-subscale correlations are frequently indicative of constructs that are not distinct, which is not the case here. The chi-square difference tests were significant $\left(\chi^{2}>3.84, d f=1, p>0.05\right)$ between 9 of the 10 construct pairings (with the 10th variable $p=0.076, d f=1$, showing a strong trend). This indicates that the constructs demonstrate high discriminant validity. In conclusion, considering both the correlation between constructs and the significant chi-square difference tests of the 5 subscales, there is strong evidence of discriminant validity among the five PTGI constructs.

\subsection{PT GI 10-Item Short Form (PTGI-SF)}

The 10-item version of the PTGI [22] was also tested for applicability with respect to the French translation. A reliability analysis of the PTGI-SF with our data indicated a high level of internal consistency of the ten items $(\alpha$ $=0.87$ ). The average inter-item correlation was $r=0.42$. In the PTGI-SF each of the five subscales is measured with two items and the correlations between the items in the 5 pairs was significant $(p<0.01)$ and ranged from $r$ $=0.40$ to $r=0.77$. To confirm the underlying factor structure of the PTGI-SF two CFA models were tested as described by Cann et al. The first model specified that a single latent construct underlies the entire 10-item scale. Unlike Cann et al.'s findings this model fit the French data well. The model's chi-square was non-significant $\left(\chi^{2}\right.$ 
Table 4. Discriminant validity.

\begin{tabular}{cccccc}
\hline & & \multicolumn{3}{c}{ Chi-square statistic } \\
\hline Comparison & Correlation & Constrained & Non-constrained & Difference & $p$-value $(\mathrm{df}=1)$ \\
\hline New Poss-RelOth & 0.41 & 169.97 & 174.6 & 4.63 & 0.031 \\
New Poss-Strength & 0.28 & 73 & 78.79 & 5.79 & 0.016 \\
New Poss-App life & 0.48 & 31.8 & 37.9 & 6.1 & 0.014 \\
New Poss-Spirit & 0.24 & 37.54 & 48.04 & 10.5 & 0.001 \\
RelOth-Strength & 0.32 & 71 & 74.14 & $3.14 *$ & 0.076 \\
RelOth-App life & 0.24 & 98.43 & 111.01 & 12.58 & 0.000 \\
RelOth-Spirit & 0.4 & 77.22 & 81.36 & 4.14 & 0.042 \\
Strength-App life & 0.17 & 29.49 & 42.19 & 12.7 & 0.000 \\
Strength-Spirit & 0.23 & 20.03 & 30.66 & 10.63 & 0.001 \\
App life-Spirit & 0.21 & 13.5 & 23.71 & 10.21 & 0.001 \\
\hline
\end{tabular}

$=29.86, d f=30, p=0.47$ ) which indicates that the covariance structure implied by the single construct model does not significantly vary from the covariance structure calculated from our French data set, indicating a good fit. Similarly, the fit estimates indicated good fit, NFI $=0.93$, RMSEA $=0.000, \mathrm{CFI}=1.00, \mathrm{IFI}=1.00, \mathrm{NNFI}=$ 1.00 and $\mathrm{RMR}=0.066$. All the loadings presented in Table 5 were significant and moderately large indicating that they contribute substantially to measuring the underlying PTGI construct.

In the second model, the 10-item, 5-factor structure suggested by Cann et al. [22] was tested by loading each pair of measurement variables on their corresponding latent construct. The model's chi-square was non-significant $\left(\chi^{2}=26.93, \mathrm{df}=25, p=0.36\right)$ which indicates that the covariance structure implied by the single construct model does not significantly vary from the covariance structure calculated from our French data set, indicating a good fit. Similarly, the fit estimates indicated good fit, NFI $=0.94$, RMSEA $=0.041$, CFI $=1.00$, IFI $=1.00$, NNFI $=0.99$ and RMR $=0.072$. The coefficients presented in Table 5 were also significant and moderately large. Thus, the 10-item 5-factor structure seems to fit the data collected from the study's French translation of the PTGI well.

In summary, both of Cann et al.'s [22] models fit well. The first model indicated that all ten items contributed significantly to the measurement of the PTGI-SF. The second model indicated that that five-factor structure was appropriate and that all items significantly contributed as did all subscale constructs to the measurement of the PTGI-SF construct.

\section{Discussion}

\subsection{Strengths}

The major contributions of this study were threefold: it establishes the validity of the translation of the PTGI into French; it verifies the proposed five-factor model of the PTGI; it uses statistical analyses with a level of rigour not previously observed in translations of the posttraumatic growth tool.

The findings of this study suggest that the French translation of the PTGI is valid and reliable for measuring posttraumatic growth. The effect sizes were large and statically significant with this moderate sample size $(\mathrm{n}=$ 47). As global interest for posttraumatic growth increases, it is important that researchers are able to examine the phenomenon in a large variety of languages and cultural settings. As Weiss and Berger ([43], p. xxii) note: "reliable and valid culture-relevant instruments to measure PTG [posttraumatic growth] are critical to guiding practitioners around the world in their efforts to accompany those exposed to stressor events in the journey to recovery and support their attempts to grow". This translation of the PTGI into French and the establishment of its reliability and validity add therefore to the increasing numbers of tools available to global health researchers and practitioners. 
Table 5. The PTGI-SF.

\begin{tabular}{ccc}
\hline (n=47) & $\begin{array}{c}\text { Coefficients } \\
\text { model 1 }\end{array}$ & $\begin{array}{c}\text { Coefficients } \\
\text { model 2 }\end{array}$ \\
Question 11 & 0.91 & 0.83 \\
Question 7 & 0.72 & 0.65 \\
Question 8 & Relating to others & \\
Question 20 & 0.77 & 0.88 \\
& 0.61 & 0.69 \\
Question 10 & Personal strength & 0.73 \\
Question 19 & 0.53 & 1.00 \\
& 0.71 & 0.75 \\
Question 14 & Appreciation of life & 0.95 \\
Question 2 & 0.49 & 0.70 \\
& 0.46 & 0.64 \\
\hline
\end{tabular}

The process of translation and back translation were performed by two separate certified translators. This is an important aspect as these professionals are trained to deal with the nuances of various languages. Content validity was determined by a native French language speaker. As Mollica et al. stated, "comparison and consensus of translation and back translation by an expert group leads to a highly valid and reliable instrument" ([44], p. 9). The translated PTGI was then administered to two populations of caregivers.

Another of the major strengths of this study is the rigorous analysis that was undertaken to establish the psychometric properties of the French translation of the PTG scale. Table 6 displays a summary of the statistical approaches to analyzing reliability and validity reported in other published papers describing the psychometric properties of PTGI language translations. All of the studies report reliability of the full scale but only two translations report subscale reliability and inter-item correlations. Of those that conducted factor analyses, all but one conducted only EFAs. As noted previously EFA is not the recommended analysis for factor analysis with a theoretical presupposition. The results of the EFAs for the five studies were varied and contradictory. The Spanish article [19] reported a three-factor structure with 13 of the items not loading on the appropriate construct as hypothesized by Tedeschi and Calhoun [3]. Rosner et al. [27] reported that the Bosnian version had a threefactor structure with nine items failing to load on their designated construct. The Chinese version [26] had a three-factor structure with six items not loading. Finally, the Japanese version [24] reported a four-factor structure having removed three items. A CFA was also conducted with the Japanese translation, wherein three items did not converge. None of these translations reported convergent or discriminant validity which precluded discussion of the scale items' unidimensionality and discreteness, respectively. The Portuguese translation [23] reported a five-factor structure as well as discriminant validity. Only the Dutch translation article reported on criterion validity [25].

Overall, concerning the 21 item version of the translated PTGI and each of the five subscales, reliability was indicated with values above the recommended minimum for exploratory studies [40]. The exception once again was item 12 in the subscale of Personal Strength. When this item was removed the subscale demonstrated high 
Table 6. Statistical tests of other translations.

\begin{tabular}{|c|c|c|c|c|c|c|c|c|}
\hline \multirow[t]{2}{*}{ Language } & \multicolumn{8}{|c|}{ Statistical tests performed } \\
\hline & $\begin{array}{l}\text { Reliability } \\
\text { (alpha) of } \\
\text { total scale }\end{array}$ & $\begin{array}{l}\text { Reliability } \\
\text { (alpha) of } \\
\text { subscales }\end{array}$ & $\begin{array}{l}\text { Inter-item } \\
\text { correlation }\end{array}$ & $\begin{array}{l}\text { Exploratory factor } \\
\text { analysis of principle } \\
\text { component analyses }\end{array}$ & $\begin{array}{c}\text { Confirmatory } \\
\text { factor analysis } \\
(\mathrm{CFA})\end{array}$ & $\begin{array}{c}\text { Convergent } \\
\text { validity (CFA) }\end{array}$ & $\begin{array}{l}\text { Discriminant } \\
\text { validity }\end{array}$ & $\begin{array}{c}\text { Criterion } \\
\text { validity (with } \\
\text { other scales) }\end{array}$ \\
\hline Dutch & Yes & Yes & Yes & No & No & No & No & Yes \\
\hline Spanish & Yes & No & No & $\begin{array}{c}\text { Yes } 3 \text { factor } 13 \text { loaded } \\
\text { differently }\end{array}$ & No & No & No & No \\
\hline${ }^{*}$ Bosnian & No & No & No & $\begin{array}{l}3 \text { factor } 9 \text { loaded } \\
\text { differently }\end{array}$ & No & No & No & No \\
\hline${ }^{*}$ Chinese & Yes & No & No & $\begin{array}{l}3 \text { factor } 6 \text { loaded } \\
\text { differently }\end{array}$ & No & No & No & No \\
\hline${ }^{*}$ German & Yes & No & No & No & No & No & No & No \\
\hline Japanese & Yes & Yes & Yes & $\begin{array}{l}4 \text { factors } 3 \text { items } \\
\text { removed }\end{array}$ & $\begin{array}{c}\text { Yes } \\
3 \text { items removed }\end{array}$ & No & No & No \\
\hline Portuguese & Yes & Yes & Yes & Yes & No & No & Yes & Yes \\
\hline PTG-SF & Yes & Yes & Some & No & Yes & Yes & No & PTG/PTG-SF \\
\hline
\end{tabular}

*Data obtained from secondary sources.

internal reliability. Confirmatory factor analyses indicated satisfactory evidence of convergent and discriminant validity. Nine of the ten construct pairings comprising the translated PTGI subscales were significant, which indicates that the constructs demonstrate high discriminant validity. The tenth variable pair (relating to othersspirituality) showed a strong trend. A larger sample size would likely mitigate this issue.

In addition, we tested the data with the shortened version of the PTGI, the PTGI-SF [22]. Inter-item correlations were moderate and a high level of internal consistency (Chronbach's alpha) was indicated. Cann et al. [22] tested two different models of underlying factor structures that we replicated. The first 10-item single construct model, and the five-factor structure model fitted well, and all items loaded significantly, indicating that they all contributed significantly to the measurement of the PTGI-SF. Therefore, the French translation of the PTGI-SF is also valid and reliable.

\subsection{Limitations}

One concern that this study revealed is the use of item 12, which asks respondents how much they have experienced the change "I am better able to accept the way things work out". However, these concerns were limited to the reliability of the Personal Strength subscale, which was $\alpha=0.34$; however, when item 12 was removed, the subscale had an internal reliability of $\alpha=0.77$, which is quite reasonable. Conversely, the convergent validity as tested by the CFA of the personal strength subscale indicated that the loading of item 12 was significant and contributed significantly to the measurement of personal strength construct. Thus, even with item 12, the personal strength scale demonstrated convergent and discriminant validity and was uni-dimensional. Thus, we cannot suggest that Item 12 does not have a significant role to play in measuring Personal Strength nor can we recommend its removal. Item 12 is not included in the PTGI-SF; thus, it was not an issue there. To assess these reliability concerns, the translation of item 12 was verified and its semantic validity was also confirmed. However, it was possible that accepting how things work out is culturally bound. Some groups may be more fatalistic than others because of cultural and/or religious beliefs [45] [46] and French-speaking cultures may well fall into this realm. It is also possible that experiencing a change in the area of accepting how things work out may not be pertinent. Although both the 10- and 21-item versions of the French translation of the PTGI scales as a whole demonstrate very good psychometric properties, further attention and possibly replacement with a more culturally appropriate translation of this item may be warranted. Although the French translation of item 12 in this study gave some concern, issues of this nature are not unique, with the Japanese version having three items (1, 11 , and 20) removed from their translation [24].

Although the power of the test was large and the effects large and significant with the current sample size, the overall populations from which we drew our sample, namely French-speaking caregivers of children with life 
limiting illnesses or of someone with HIV/AIDS, is small. Future researchers should replicate this study both with caregivers and with other French populations who experience posttraumatic growth.

A second limitation of this study is its moderate sample size. To address this we undertook the comparison with our larger English sample and found that there were not significant differences in the subscales. However, because of the expensive budget required for translations and the lengthy process of consultation, studies of cross cultural validation of instruments are often conducted with small samples. For instance, the inter-rater reliability of the Icelandic version of the Schedule for Affective Disorders and Schizophrenia for School-Age Children *Present and Lifetime Version (Kiddie-SADS-PL) was assessed on a sample of 15 individuals [47]. Thus, although the sample was of moderate size, the results were significant, indicating that the French translation has good psychometric properties.

In addition to moderate sample size, all the respondents of the current study were living in Canada. French is spoken in a large number of countries. It is of course the first language of France but it is also an official language in other multi-lingual countries, such as Canada, Belgium, and Switzerland. French is spoken in a number of African and Asian countries, such as Rwanda, Democratic Republic of Congo and Vietnam. The data from these studies is obtained exclusively from French-speaking Canadians, mostly residing in Québec, the only Canadian province with French as its only official language. There are, however, variations in the language from one country to the next as well as cultural differences and it is important to test this translation in other Frenchspeaking nations and populations.

All of those who participated in this study were caregivers of family members affected by chronic illness, a specific source of traumatic stress. The caregiving of the respondents may also be a limitation in this study. Most of the posttraumatic growth research focuses on events that are distinct in time. While grief and living with an illness such as a cancer are frequent circumstances that figure large in the literature, and are ongoing circumstances, these participants were caring for someone else. The growth that they experience is little understood and the scores on the PTGI may be somewhat different from people directly experiencing adverse circumstances themselves. The Portuguese translation was also validated in a population of adult caregivers [23].

Despite these limitations, this study contributes with a much needed validated French translation of the PTGI, one of the languages most used worldwide. The ability to use tools of research and practice such as the PTGI with non-English-speaking populations, enrich the work of those professions that practice with diverse communities.

\section{Conclusions}

This article constitutes three major contributions to the PTG literature. First is the establishment of a valid and reliable French version of PTGI. This is an important contribution, as French is spoken as the first or second language in many countries, including large communities in North America. The wider use of the French PTGI, in addition to the other existing translations, will enable greater depth of understanding of the concept of posttraumatic growth, allowing for greater application in research and practice. Second, this article is the first translation paper to perform a rigorous investigation of the psychometric properties of the PTGI including the scale and subscale reliability, inter-item and subscale correlations, and to use a CFA approach to establish convergent and discriminant validity and unidimensionality. Finally, this article not only establishes the psychometric properties of the 21-item PTGI, but also extends its investigation to include the 10-item PTGI-SF as proposed by Cann et al. [22].

Overall findings indicate that the French translation of the PTGI is reliable and valid in both the original and its short form. Future research is necessary to expand our understanding of the cultural aspects of posttraumatic growth. The use of validated instruments in other languages in research is an effective approach to learn more about the strengths and needs within specific cultural groups affected by traumatic stress. From a clinical perspective, multiple theoretical perspectives should be considered as developing interventions for diverse populations affected by traumatic events. The expanded use of the construct of posttraumatic growth adds a welcome resilience perspective to the dominant trauma framework, focused solely on distress. It is our hope that the French version of the PTGI will allow practitioners to develop enhanced intervention models when working with French-speaking populations worldwide impacted by traumatic events. Overall, this study presents implications for future investigations and makes a contribution to further expanding knowledge of the positive aspects of stressful experiences. 


\section{References}

[1] Seyle, H. (1976) Forty Years of Stress Research: Principal Remaining Problems and Misconceptions. Canadian Medical Association Journal, 115, 519-531.

[2] Suedfeld, P. (1997) Reactions to Societal Trauma: Distress and/or Eustress. Political Psychology, 18, 849-861. http://dx.doi.org/10.1111/0162-895X.00082

[3] Tedeschi, R.G. and Calhoun, L.G. (1996) The Posttraumatic Growth Inventory: Measuring The Positive Legacy of Trauma. Journal of Traumatic Stress, 9, 455-471. http://dx.doi.org/10.1002/jts.2490090305

[4] Jim, H.S.L. and Jacobsen, P.B. (2008) Posttraumatic Stress and Posttraumatic Growth in Cancer Survivorship: A Review. The Cancer Journal, 14, 414-419. http://dx.doi.org/10.1097/PPO.0b013e31818d8963

[5] Joseph, S. and Linley, P.A. (2006) Growth Following Adversity: Theoretical Perspectives and Implications For Clinical Practice. Clinical Psychology Review, 26, 1041-1053. http://dx.doi.org/10.1016/j.cpr.2005.12.006

[6] Linley, P.A. and Joseph, S. (2004) Positive Change Following Trauma and Adversity: A Review. Journal of Traumatic Stress, 17, 11-21. http://dx.doi.org/10.1023/B:JOTS.0000014671.27856.7e

[7] Stanton, A.L., Bower, J.E. and Low, C.A. (2006) Posttraumatic Growth after Cancer. In: Calhoun, L.G. and Tedeschi, R.G., Eds., Handbook of Posttraumatic Growth: Research and Practice, Erlbaum, Mahwah, 138-175.

[8] Tedeschi, R.G. and Calhoun, L.G. (2004) Posttraumatic Growth: Conceptual Foundations and Empirical Evidence. Psychological Inquiry, 15, 1-18. http://dx.doi.org/10.1207/s15327965pli1501 01

[9] Zoellner, T. and Maercker, A. (2006) Posttraumatic Growth in Clinical Psychology: A Critical Review and Introduction of a Two Component Model. Clinical Psychology Review, 26, 626-653. http://dx.doi.org/10.1016/j.cpr.2006.01.008

[10] Prati, G. and Pietrantoni, L. (2009) Optimisim, Social Support, and Coping Strategies as Factors Contributing to Posttraumatic Growth: A Meta-Analysis. Journal of Loss and Trauma, 14, 364-388. http://dx.doi.org/10.1080/15325020902724271

[11] Helgeson, V., Reynolds, K. and Tomich, P. (2006) A Meta-Analytic Review of Benefit Finding and Growth. Journal of Counseling and Clinical Psychology, 74, 797-816. http://dx.doi.org/10.1037/0022-006X.74.5.797

[12] Cadell, S. (2012) Stress, Coping, Growth and Spirituality in Grief. In: Groen, J., Coholic, D. and Graham, J., Eds., Spirituality in Education and Social Work: An Interdisciplinary Dialogue, Wilfrid Laurier Press, Waterloo, 217-232.

[13] Cadell, S., Shermak, S. and Johnston, M. (2011) Discovering Strengths and Growth in Palliative Care. In: Altilio, T. and Otis-Green, S., Eds., Oxford Textbook of Palliative Social Work, Oxford University Press, New York, 215-222. http://dx.doi.org/10.1093/med/9780199739110.003.0020

[14] Cadell, S., Regehr, C. and Hemsworth, D. (2003) Factors Contributing to Posttraumatic Growth: A Proposed Structural Equation Model. The American Journal of Orthopsychiatry, 73, 279-287. http://dx.doi.org/10.1037/0002-9432.73.3.279

[15] Grubaugh, A.L. and Resick, P.A. (2007) Post-Traumatic Growth in Treatment-Seeking Female Assault Victims. Psychiatric Quarterly, 78, 145-155. http://dx.doi.org/10.1007/s11126-006-9034-7

[16] Kleim, B. and Ehlers, A. (2009) Evidence for a Curvilinear Relationship between Post-Traumatic Growth and Post-Trauma Depression and PTSD in Assault Survivors. Journal of Traumatic Stress, 22, 45-52. http://dx.doi.org/10.1002/jts.20378

[17] Cadell, S., Kennedy, K. and Hemsworth, D. (2012) Informing Social Work Practice through Research with Parent Caregivers of a Child with a Life-Limiting Illness. Journal of Social Work in End-of-Life and Palliative Care, 8, 356-381. http://dx.doi.org/10.1080/15524256.2012.732021

[18] Cadell, S., Hemsworth, D., Quosai, T.S., Steele, R., Davies, B., Liben, S., Straatman, L. and Siden, H. (2014) Posttraumatic Growth in Parents Caring for a Child with a Life-Limiting Illness: A Structural Equation Model. American Journal of Orthopsychiatry, 84, 123-133. http://dx.doi.org/10.1037/h0099384

[19] Weiss, T. and Berger, R. (2006) Reliability and Validity of a Spanish Version of the Posttraumatic Growth Inventory. Research on Social Work Practice, 16, 191-199. http://dx.doi.org/10.1177/1049731505281374

[20] Keinan, G., Shrira, A. and Shmotkin, D. (2012) The Association between Cumulative Adversity and Mental Health: Considering Dose and Primary Focus of Adversity. Quality of Life Research, 21, 1149-1158. http://dx.doi.org/10.1007/s11136-011-0035-0

[21] Robinson, J.S. and Larson, C. (2010) Are Traumatic Events Necessary to Elicit Symptoms of Posttraumatic Stress? Psychological Trauma: Theory, Research, Practice, and Policy, 2, 71-76. http://dx.doi.org/10.1037/a0018954

[22] Cann, A., Calhoun, L.G., Tedeschi, R.G., Taku, K., Vishnevsky, T., Triplett, K.N. and Danhauer, S.C. (2010) A Short Form of the Posttraumatic Growth Inventory. Anxiety, Stress, and Coping, 23, 127-137. 
http://dx.doi.org/10.1080/10615800903094273

[23] Teixeira, R.J. and Pereira, M.G. (2013) Growth and the Cancer Care Giving Experience: Psychometric Properties of the Portuguese Posttraumatic Growth Inventory. Families, Systems, and Health, 31, 382-395. http://dx.doi.org/10.1037/a0032004

[24] Taku, K., Calhoun, L.G., Tedeschi, R.G., Gil-Rivas, V., Kilmer, R.P. and Cann, A. (2007) Examining Posttraumatic Growth among Japanese University Students. Anxiety, Stress, and Coping, 20, 353-367. http://dx.doi.org/10.1080/10615800701295007

[25] Jaarsma, T.A., Pool, G., Sanderman, R. and Ranchor, A.V. (2006) Psychometric Properties of the Dutch Version of the Posttraumatic Growth Inventory among Cancer Patients. Psycho-Oncology, 15, 911-920. http://dx.doi.org/10.1002/pon.1026

[26] Ho, S., Chan, C. and Ho, R. (2004) Posttraumatic Growth in Chinese Cancer Survivors. Psycho-Oncology, 13, $377-389$. http://dx.doi.org/10.1002/pon.758

[27] Rosner, R., Powell, S. and Butollo, W. (2003) Posttraumatic Stress Disorder Three Years after the Siege of Sarajevo. Journal of Clinical Psychology, 59, 41-55. http://dx.doi.org/10.1002/jclp.10116

[28] Maercker, A. and Langner, R. (2001) Posttraumatic Personal Growth: Validation of German Versions of Two Questionnaires. Diagnostica, 47, 153-162. http://dx.doi.org/10.1026//0012-1924.47.3.153

[29] Lev-Wiesel, R. and Amir, M. (2003) Posttraumatic Growth among Holocaust Child Survivors. Journal of Loss and Trauma, 8, 229-237. http://dx.doi.org/10.1080/15325020305884

[30] Lelorain, S., Bonnaud-Antignac, A. and Florin, A. (2010) Long Term Posttraumatic Growth after Breast Cancer: Prevalence, Predictors and Relationships with Psychological Health. Journal of Clinical Psychology in Medical Settings, 17, 14-22. http://dx.doi.org/10.1007/s10880-009-9183-6

[31] Bollen, K.A. (1989) Structural Equations with Latent Variables. Wiley-Interscience, New York. http://dx.doi.org/10.1002/9781118619179

[32] Hair, J., Anderson, R., Tatham, R. and Black, W. (1988) Multivariate Data Analysis. 5th Edition, Prentice Hall, Upper Saddle River.

[33] Long, J.S. (1983) Confirmatory Factor Analysis: A Preface to LISREL. Sage Publications, Beverly Hills.

[34] Lucas-Carrasco, R., Gomez-Benito, J., Rejas, J. and Brod, M. (2011) The Spanish Version of the Dementia Quality of Life Questionnaire: A Validation Study. Aging and Mental Health, 15, 482-489. http://dx.doi.org/10.1080/13607863.2010.543658

[35] Cadell, S. (2001) Posttraumatic Growth in HIV/AIDS Caregivers in Quebec. Canadian Social Work, 3, 86-94.

[36] Cadell, S. (2003) Trauma and Growth in Canadian Carers. AIDS Care, 15, 639-648. http://dx.doi.org/10.1080/09540120310001595122

[37] Cadell, S. (2007) The Sun Always Comes out after It Rains: Understanding Posttraumatic Growth in HIV Carers. Health and Social Work, 32, 169-176. http://dx.doi.org/10.1093/hsw/32.3.169

[38] Cadell, S. and Sullivan, R. (2006) Posttraumatic Growth and HIV Bereavement: Where Does It Start and When Does It End? Traumatology, 12, 45-59. http://dx.doi.org/10.1177/153476560601200104

[39] Schneider, M., Steele, R., Cadell, S. and Hemsworth, D. (2011) Differences on Psychosocial Outcomes between Male and Female Caregivers of Children with Life-Limiting Illnesses. Journal of Pediatric Nursing, 26, 186-199. http://dx.doi.org/10.1016/j.pedn.2010.01.007

[40] Churchill, G. (1979) A Paradigm for Developing Better Measures of Marketing Constructs. Journal of Marketing Research, 16, 64-73. http://dx.doi.org/10.2307/3150876

[41] Anderson, J. and Gerbing, D. (1988) Structural Equation Modelling in Practice: A Review and Recommended TwoStep Approach. Psychological Bulletin, 103, 411-423. http://dx.doi.org/10.1037/0033-2909.103.3.411

[42] Segars, A. and Grover, V. (1993) Re-Examining Perceived Ease of Use and Usefulness: A Confirmatory Factor Analysis. MIS Quarterly, 17, 517-525. http://dx.doi.org/10.2307/249590

[43] Weiss, T. and Berger, R. (2010) Posttraumatic Growth and Culturally Competent Practice. John Wiley and Sons Inc., Hoboken. http://dx.doi.org/10.1002/9781118270028

[44] Mollica, R.F., Mcdonald, L.S., Masagli, M.P. and Silove, D.M. (2004) Measuring Trauma Measuring Torture: Instructions and Guidance on the Utilization of the Harvard Program in Refugee Trauma's Versions of the Hopkins Symptom Checklist-25 (HSCL-25), The Harvard Trauma Questionnaire (HTQ). Harvard Program in Refugee Trauma, Cambridge.

[45] Morgan, P.D., Tyler, I.D. and Fogel, J. (2008) Fatalism Revisited. Seminars in Oncology Nursing, 24, $237-245$. http://dx.doi.org/10.1016/j.soncn.2008.08.003 
[46] Young, M.J., Morris, M.W., Burrus, J., Krishnan, L. and Regmi, M.P. (2011) Deity and Destiny: Patterns of Fatalistic Thinking in Christian and Hindu Cultures. Journal of Cross-Cultural Psychology, 42, 1030-1053. http://dx.doi.org/10.1177/0022022110381123

[47] Lauth, B., Magnússon, P., Ferrari, P. and Pétursson, H. (2008) An Icelandic Version of the Kiddie-SADS-PL: Translation, Cross-Cultural Adaptation and Inter-Rater Reliability. Nordic Journal of Psychiatry, 62, 379-385. http://dx.doi.org/10.1080/08039480801984214 